\title{
Integrating Creativity in the Facilitation of Adult Learning through Analytic and Synthetic Methods: Study of Adult Basic Literacy Education Program in Enugu State, Nigeria
}

\author{
Dorida Nneka Oyigbo ${ }^{1}$, K. Chukwuemeka Obetta ${ }^{1}$, Chinasa M. Ugwunnadi ${ }^{1}$, J. O. Acha ${ }^{2}$, \\ Onyinyechi E. Okoye ${ }^{1} \&$ B. N. Onah ${ }^{1}$ \\ ${ }^{1}$ Department of Adult Education and Extra-Mural Studies, University of Nigeria, Nsukka, Enugu State, Nigeria \\ ${ }^{2}$ Department of Continuing Education and Development Studies, University of Calabar, Nigeria \\ Correspondence: Dr. Obetta, K. Chukwuemeka, Department of Adult Education and Extra-Mural Studies, \\ University of Nigeria, Nsukka, Enugu State, Nigeria. Tel: 234-803-776-4740. E-mail: \\ chukwuemeka.obetta@unn.edu.ng
}

Received: July 16, 2020 Accepted: August 25, 2020 Online Published: October 22, 2020

doi:10.5539/gjhs.v12n12p70

URL: https://doi.org/10.5539/gjhs.v12n12p70

\begin{abstract}
Adult basic literacy education program requires the integration of creativity into learning activities to increase the rate of adult learning in adult basic literacy education program. The study assessed the extent of integrating creativity in facilitating adult learners in adult basic literacy education program. The study adopted a descriptive survey design. The instrument titled, Integrating Creativity in the Facilitation of Adult Learning through Analytic and Synthetic Methods Questionnaire was administered to 880 adult education administrators, adult literacy facilitators and adult learners. Data were presented through the use of mean, standard deviation and ANOVA. The results of the study revealed that integrating analytic and synthetic methods to a moderate extent facilitated the learning of adults in an adult basic literacy education program. The study recommended that state agency for mass literacy, adult and non-formal education should encourage adult literacy facilitators to create personalized programs of instruction and lesson plans that are based on the adult learners' skill level and learning styles.
\end{abstract}

Keywords: integrating creativity, adult basic literacy education program, facilitation of adult learning, analytic method, synthetic method

\section{Introduction}

Adult basic literacy education program (ABLEP) is an integral section of adult education programs (AEPs) designed for adults to bring about change in knowledge, skills and attitudes. The World Education Forum of 2015 organized in Incheon, Republic of Korea, adopted the Education Framework for Action which mandated countries of the world to achieve Sustainable Development Goal, number 4 (SDG4) by 2030 (United Nations' Educational, Scientific and Cultural Organization Global Education Monitoring Report, UNESCO-GEMR, 2016). The goal number 4 centered on inclusive and equitable quality education and lifelong learning for everyone. SDG4, declaration 9 requires that qualified and skilled teachers, facilitators, and educators should be empowered through proper recruitment and training. They should be inspired and assisted within well-resourced, secured and effectively controlled structures. In 2015, the Global Education Monitoring (GEM) recorded that 758 million people, 114 million of whom are aged 15 to 24, were unable to read or write a simple sentence (Berdie, 2017). Hence, it is the role of an educational agent to ensure that quality and equitable learning is achieved for all the adult learning participants (Bhola, 2000; Biney, 2014).

The objectives of mass literacy, adult and non-formal education among others include the provision of equivalent functional basic education (from primary to junior secondary school) for adults and youth who have never had the advantage of formal schooling or who have left school too early (Federal Republic of Nigeria, FRN, 2013). The targeted classes are migrants, almajiri, parents, youth and teenagers who are illiterate and semi-literate, and people who left the formal school system early and are now ready to return and start schooling. Other focus groups are those that are unable to enter the traditional education system and thus, need other types of educational services to meet their specific needs. Therefore, ABLEP is a way of combating man's isolation from educational opportunities. The program helps adult learners to acquire sustainable literacy skills that enable them to fully participate in 
socio-economic development activities (Audi, Ayodo, Simatwa, \& Othuon, 2014). ABLEP facilitates the acquisition of relevant knowledge and skills. The program also facilitates the adaptation of new technologies and production skills. This leads to increased awareness, safety, competencies, better organization, and life management (Audi, Ayodo, \& Simatwa, 2014).

Lesgold and Welch-Ross (2012) noted that there are several reasons why adults are keen to improve their literacy skills. Many study to receive a Diploma certificate which is high school equivalence. Others aim to support their children and families with matters of schooling, health and other practical life, while few others work to learn English Language or develop skills for new job responsibilities. Others may have a higher level of literacy but the required reading and writing skills in school have not yet been developed. The cycle of gaining these qualities is part of basic education (from primary to junior secondary), which is considered to be a fundamental human right and a prerequisite for the development of man.

The functional approach to the provision of ABLEP was adopted to establish systematic connections between the participants' literacy and their daily activities. It provides the literacy beneficiaries with sufficient information and skills to solve different problems in their societies. ABLEP's approach was to make it work-oriented, and to promote and stimulate integrated growth, particularly in rural areas (Audi, Ayodo, \& Simatwa, 2014). ABLEP systematically transfers knowledge and skills directly to the learners. This is to improve their living conditions in terms of growth, hygiene, sanitation, environmental protection and family planning among other things. Therefore, one of the main types of literacy instruction that AEPs provides is an adult basic literacy education program (ABLEP) which offers instruction to adults who lack the skills to read, write, communicate, problem-solve or calculate at the required level to operate in the family, at work or in society (Lesgold \& Welch-Ross, 2012).

ABLEP is a literacy program of reading, writing and counting that is organized for literacy beginners. Obidiegwu (2013) stated that ABLEP is all-organized reading, writing and numeracy skills designed for adults for their personal and societal fulfillment which will enable them to adapt to the constantly changing global requirements and marginalization. Also, Ezema, Ukwuaba and Ali (2018) affirmed that basic literacy as an AEP encompasses developing the adults' mind, knowledge, attitudes and skills capable of solving personal and societal problems. Development is achieved through the facilitation of learning of adults in ABLEP.

Facilitation is a process of helping adults to share ideas and learn those things, which will help them to solve their individual, family or societal problems. According to Kamp (2011), facilitation is a mechanism that allows people to exchange ideas, resources and perspectives while at the same time being objective and constructive. It is essential that when working in ABLEP, the learning facilitation strategy is acceptable and the learning opportunity outcomes are informative and beneficial to adult learners.

The development of AEPs in different settings is expected to increase the considerations for adult learners. Andragogy, which is the method of promoting adult learning, is also intended to become the basis for basic education and training (ABET). Andragogy demands that the learners' learning styles serve as the basis on which learning experiences are developed (Machobane, 2010). However, there is every likelihood that many of the facilitators often use pedagogical approaches to promote adult learning, rather than andragogical ones. Andragogy puts instruction at the core of teaching-learning. It requires facilitators to be versatile in terms of reacting to the learning needs of adult learners and the perceptiveness that enables them to adjust to the different learning styles of adult learners (Machobane, 2010).

To encourage active learning of ABLEP, it becomes necessary that adult literacy facilitators (ALFs) need to integrate creativity in the methods of facilitating adult learning. This is because ABLEP is based on the realization that teaching adults (andragogy) requires an approach and methodology different from teaching children and adolescents (pedagogy) (Kamp, 2011). Integrating creativity in the methods of facilitating adult learning presupposes an active role of the learners and new roles for the facilitators to make learning interesting (Bocconi, Kampylis, \& Punie, 2012). Integration is the act of bringing together smaller components into a single system that functions as one. Integration indicates that there is further strengthening of relations within a social system, which also relates to additional actors or groups in an existing social system and its core institutions (Heckmann, 2004). It is also regarded as the process of becoming an accepted part of society as it is the inclusion of individual actors in an already existing social system (Penninx \& Garcés-Mascareñas, 2016). In this study, integration means the progressive transition from a less coherent state to a more coherent one.

The integration of creative methods in the facilitation of adult learning ensures that facilitators create effective learning activities that increase the rate at which the learners of ABLEP learn. Chandrasekar (2002) stated that in India, the reading and writing methods of facilitation are graded into analytic, synthetic, and analytico-synthetic methods. However, there are two main thinking structures of the brain that facilitate learning. They are A-quadrant 
(analytic method) and B-quadrant (synthetic method) (Carter, 2000; Du Toit, 2002; Meneely \& Portillo, 2005). On the analytic method as creative method of facilitating learning in ABLEP, National Commission for Mass Literacy, Adult and Non-formal Education, NMEC (2012) affirmed that individual words and groups are analyzed into letters and letter combinations or syllables.

The analytic method applies to the theoretical process of separating into its constituent components the larger units. This requires a wider structure, which can be divided into words, syllables and letters (Chandrasekar, 2002). Accordingly, the method attempts to develop among adult learners the habit of seeing words and sentences as a whole and then slowly starts to recognize letters. The analytic method (A-quadrant) shows that an individual prefers activities that require knowledge based on analytics and facts (Machobane, 2010). A person like that prefers to learn from the lectures and textbooks. Learning using this method starts with small sentences, stories that will be broken into letters of alphabets. In the analytic method, the facilitator begins the literacy session by making the learners to recognize the word, phrase, and sentence as a whole by reducing them into letters and syllables, thereby providing the basis for studying small units through the understanding of the larger units (Nzeneri, 2008). Analytic method centers on applying established approaches and models to resolve problems that concern adult learners and the structure of organizational learning by achieving mastery of the learning task through structural exercises and making learners write what they have been taught (Bienkowski, Feng, \& Means, 2012). Analytic method tailors educational resources to the needs and abilities of adult learners through acts like teaching adult learners to write what they have been taught and introducing large elements of language before small elements (Chandrasekar, 2002; Nzeneri, 2008; Scheffel, Drachsler, Stoyanov, \& Specht, 2014).

The synthetic method is another type of creative method of facilitating learning in ABLEP. NMEC (2012) stated that facilitators employ the alphabet of language to teach reading to adult beginners in ABLEP. The synthetic method begins teaching reading and writing with the simplest elements of language and proceeds to the largest units, the introduction of vowels before consonants, and use of pictures and objects resembling the letters (Okenimkpe, 2003). The larger units themselves provide the basis or context for the studying of the small units. The adults are taught to construct words by combining the letters already mastered, often even by these combinations rendering meaningless 'names'. Besides, an image of an entity is shown to the adults and they are told to pronounce the entity's name (Chandrasekar, 2002). A synthetic method (B-quadrant) shows that an individual prefers coordinated, sequential, expected, and comprehensive information (Machobane, 2010). A person like that prefers to learn better through step-by-step methodical review of what is learned, as well as practice and repetition to develop abilities and skills. The synthetic method begins facilitating reading and writing with mastery of letters of alphabets to a combination of letters (syllables) to words, phrases, and sentences.

Nzeneri (2008) asserted that synthetic method guides learners to recognize that letters are combined to form a syllable; syllables are combined to form a word, while words are combined to form a phrase and then a sentence. The technique starts literacy lesson by using alphabets or letters of the alphabets, learning the syllable block, their sounds and pronunciations and then advance into combining them to form a whole, which is word, phrase, or sentence. If the learners know certain sounds, they can use the information to read words by decoding, or write words by encoding, as they can build up and break down words (Ehri, Nunes, Stahl, \& Willows, 2001). Synthetic method seeks to consolidate letter sounds first, before blending the sounds together to achieve full pronunciation of whole words. It therefore associates letters with the speech sounds which the letters represent, and describes how consonants are combined with vowels (Obi, 2006). Ehri et al. (2001) affirmed that synthetic method is based on facilitating to the learners the sounds of the 44 phonemes in English sequentially and the corresponding letters, from the simplest elements of the language to the highest one.

In Enugu State of Nigeria, adult literacy program exists in all the 17 local government areas. The state agency for mass literacy, adult and non-formal education (SAME) is responsible for establishing, monitoring, supervising and regulating AEP in the state (FRN, 2013). SAME which is under NMEC is saddled with the responsibility of eradicating illiteracy within the shortest possible time. The adult education administrators (comprising coordinators, alternate coordinators, and supervisors) at the local government levels are responsible for the monitoring, supervision and day-to-day control and administration of the program. In an attempt to achieve the objectives of the agency, it is the responsibility of adult education administrators (AEAs) to ensure that adult literacy facilitators (ALFs) integrate creativity in the methods of facilitating adult learning. The creative techniques integrated include analytic and synthetic methods (Odo, 2015). It is in line with the assertion of the FRN (2013) that various creative and inventive methods need to be employed to eliminate analphabetism in the shortest possible time, instead of the conventional form of alphabet learning. There are, however, several anecdotal reports of low attendance and high ABLEP dropout rates in Enugu State (Obetta \& Oreh, 2018). 
It is important that when working in ABLEP, the methods of facilitating learning are appropriate and that the outcomes of the learning opportunities are interesting and useful to the adults. To the best of the researchers' knowledge, there is no empirical evidence to show that studies have been carried out in Enugu State on the extent to which creativity has been integrated into facilitating adult learning through analytic and synthetic methods in ABLEP. Against this background, the problem of this study posed as a question was: To what extent does the integration of creative methods facilitate adult learning in ABLEP in Enugu State, Nigeria.

\subsection{Purpose of the Study}

The purpose of the study is to assess the integration of creativity in facilitating learning of adults in ABLEP in Enugu State, Nigeria. The specific objectives of the study were to:

1. Ascertain the extent to which integrating analytic method facilitate the learning of adults in ABLEP in Enugu State.

2. Ascertain the extent to which integrating synthetic method facilitate the learning of adults in ABLEP in Enugu State.

\subsection{Research Questions}

The following research questions guided the study:

1. To what extent does integrating analytic method facilitate the learning of adults in ABLEP in Enugu State?

2. To what extent does integrating synthetic method facilitate the learning of adults in ABLEP in Enugu State?

\subsection{Hypotheses}

The following hypotheses were developed to direct the analysis and evaluated at a significant point of 0.05 :

$\mathrm{HO}_{1}$ : There is no significant difference among the mean ratings of the adult education administrators, adult literacy facilitators, and adult learners on the extent to which integrating analytic method facilitates the learning of adults in ABLEP in Enugu State.

$\mathrm{HO}_{2}$ : There is no significant difference among the mean ratings of the adult education administrators, adult literacy facilitators, and adult learners on the extent to which integrating synthetic method facilitates the learning of adults in ABLEP in Enugu State.

\section{Materials and Methods}

A descriptive survey research design was adopted for the study. The survey design is a quantitative research technique in which a researcher administers a questionnaire to a sample or to the entire population to identify the population's behaviors, beliefs, expectations, or characteristics (Creswell, 2012). In this survey design, the problem was established to get accurate and reliable information and to arrive at credible findings according to the current condition and practice.

The population of the study was 4,212 respondents, comprising 228 adult education administrators (AEAs), 580 adult literacy facilitators (ALFs), and 3,404 adult learners from 116 adult literacy centers (ALCs) in Enugu State (Enugu State Agency for Mass Literacy Adult and Non-Formal Education, ENSAME, 2019). The sample size was 1,348 respondents. In composing the sample, the researchers employed a stratified random sampling technique to pick three out of the six education zones in Enugu State. They are Nsukka Education Zone (Nsukka, Igbo-Etiti and Uzo-Uwani Local Government Areas); Udi Education Zone (Udi and Ezeagu Local Government Areas), and Enugu Education Zone (Enugu North, Enugu East, and Isi-Uzo Local Government Areas). The three education zones selected have a total of eight local government areas comprising 116 AEAs, 175 ALFs, and 1,057 adult learners. This represents 32 percent of the entire population.

The instrument used for data collection was a 12-item structured questionnaire titled, "Integrating Creativity in the Facilitation of Adult Learning through Analytic and Synthetic Methods (ICFALASM) Questionnaire". A rating scale of 4 points was used to characterize the respondents' views, and the rating scales were assigned numerical values of 4 points. The instrument was face-validated by three research method experts. They made corrections and modifications on the phrasing of the objects, the degree of language, their importance to the question and the study objectives.

The researchers carried out a survey on 19 respondents (three AEAs, six ALFs, and ten adult learners) in the Obollo-Afor Education Zone of Enugu State, Nigeria. This was done to check the instrument's reliability. 
Cronbach alpha method was used to estimate the coefficient of reliability. It obtained a reliability coefficient of 0.89 , showing that the performance was high and that the instrument was accurate.

The researchers distributed to the respondents 1,348 copies of the questionnaire in their offices (for AEAs) and in ALCs (for ALFs, and adult learners). Direct distribution strategy was used to administer and collect the instrument with the aid of three qualified research assistants; 880 copies were properly filled in and returned, giving a rate of return of 65.28 percent. Results were quantitatively analyzed using statistical software (SPSS version 20) to respond to the research questions. As such, the quantitative results were analyzed using descriptive statistics (mean and standard deviation). To assess the substantial mean difference between the respondent groups, one way ANOVA was estimated at 0.05 significance point for the two hypotheses.

\section{Results}

\subsection{Research Question One}

To what extent does integrating analytic method facilitate the learning of adults in ABLEP in Enugu State?

Answers to research question one are reported in Table 1 below:

Table 1. Mean responses on the extent of integrating analytic method to facilitate the learning of adults in ABLEP $\mathrm{N}=880$

\begin{tabular}{|c|c|c|c|c|c|}
\hline $\mathbf{S} / \mathbf{N}$ & Integrating analytic method to facilitate the learning of adults & Mean Value & Std. Dev. & Rank & Decision \\
\hline 1. & Introducing large elements of language before small elements. & 3.08 & .97 & $1^{\text {st }}$ & $\mathrm{ME}$ \\
\hline 2. & $\begin{array}{l}\text { Providing the basis for studying small units through the } \\
\text { understanding of the larger units. }\end{array}$ & 3.07 & .92 & $2^{\text {nd }}$ & $\mathrm{ME}$ \\
\hline 3. & Reducing individual words and groups into letters and syllables. & 2.98 & 1.01 & $3^{\text {rd }}$ & ME \\
\hline 4. & Using not more than four words in a sentence at a time. & 2.74 & 1.05 & $6^{\text {th }}$ & $\mathrm{ME}$ \\
\hline 5. & Making learners write what they have been taught. & 2.83 & 1.01 & $4^{\text {th }}$ & ME \\
\hline 6. & Achieving mastery of the learning task through structural exercises & .2 .81 & 1.03 & $5^{\text {th }}$ & $\mathrm{ME}$ \\
\hline \multicolumn{2}{|c|}{ Grand Mean } & 2.92 & 0.80 & & ME \\
\hline
\end{tabular}

* Std. Dev. $=$ Standard Deviation; $\mathrm{ME}=$ Moderate Extent.

Table 1 presents the mean scores and standard deviations of the responses of adult education administrators (AEAs), adult literacy facilitators (ALFs), and adult learners on the extent to which integrating analytic method facilitates the learning of adults in adult basic literacy education program (ABLEP) in Enugu State, Nigeria. From the data on the Table, item 1 was ranked as highest $\left(1^{\text {st }}\right)$ and item 4 was ranked as lowest $\left(6^{\text {th }}\right)$. All the mean ratings, however, were within the actual mark of $2.50-3.49$. Items $1-6$ had mean scores of 3.08, 3.07, 2.98, 2.74, 2.83, and 2.81 , respectively. The data indicated that their mean values ranged from $2.74-3.08$, indicating that the analytic method facilitated the learning of adults to a moderate extent on the six items. The mean scores had a respective standard deviation of $0.97,0.92,1.01,1.05,1.01$, and 1.03. The standard deviation, which fell between 0.92 and 1.05 , indicated that the responses were clustered around the mean. On the whole, the grand mean $(2.92 \pm 0.80)$ showed that the respondents agreed that integrating the analytic method to a moderate extent facilitated the learning of adults in ABLEP.

Hypothesis one was tested below to further examine the different reactions among adult education administrators, adult literacy facilitators, and adult learners:

$\mathrm{H}_{1}$ : There is no significant difference between the mean ratings of the adult education administrators, adult literacy facilitators, and adult learners on the extent to which integrating analytic method facilitates the learning of adults in ABLEP in Enugu State.

To test hypothesis one, Analysis of Variance (ANOVA) was computed on the disparity between the adult education administrators, adult literacy facilitators, and adult learners, and the findings are reported in Table 2 below: 
Table 2. Summary of the ANOVA ratings of respondents on the extent of integrating analytic method to facilitate the learning of adults in ABLEP in Enugu State, Nigeria

t-Critical $=1.960$

\begin{tabular}{lllllll}
\hline & Sum of Squares & df & Mean Square & F & Sig. & Decision \\
\hline Between Groups & 21.95 & 2 & 10.97 & 17.80 & .00 & Rejected \\
Within Groups & 540.72 & 877 & .62 & & & \\
Total & 562.66 & 879 & & & \\
\hline
\end{tabular}

*df = Degree of Freedom; F = Frequency Ratio; Sig. $=$ Significant

Table 2 shows the ANOVA for testing the null hypothesis one $\left(\mathrm{H}_{1}\right)$. The result showed that the F-ratio of 17.80 was obtained, which is greater than the t-Critical value of 1.960 at significant point of 0.00 . The hypothesis was rejected, suggesting that the mean ratings of the adult education administrators, adult literacy facilitators, and adult learners differ significantly on the extent to which integrating analytic method facilitated the learning of adults in ABLEP in Enugu State, Nigeria.

\subsection{Research Question Two}

To what extent does integrating synthetic method facilitate the learning of adults in ABLEP in Enugu State?

Answers to research question two are reported in Table 3 below:

Table 3. Mean responses on the extent of integrating synthetic method to facilitate the learning of adults in ABLEP $\mathrm{N}=880$

\begin{tabular}{llllc}
\hline S/N Integrating synthetic method to facilitate the learning of adults & \multicolumn{3}{l}{ Mean Value Std. Dev. Ranks Decision } \\
\hline 7. Starting from the simplest elements of language to the highest element. & 3.18 & .90 & $1^{\text {st }}$ & ME \\
8. Using letters that are taught one by one. & 3.05 & .94 & $3^{\text {rd }}$ & ME \\
9. Using letters that are combined to form a syllable. & 3.14 & .87 & $2^{\text {nd }}$ & ME \\
10. Associating letters with the speech sounds which the letters represent. & 2.87 & .96 & $5^{\text {th }}$ & ME \\
11. Teaching vowels before consonants. & 3.05 & .91 & $3^{\text {rd }}$ & ME \\
12. Describing how consonants are combined with vowels. & 2.87 & 1.05 & $5^{\text {th }}$ & ME \\
\hline Grand Mean & $\mathbf{3 . 0 2}$ & $\mathbf{0 . 7 2}$ & & ME \\
\hline
\end{tabular}

Table 3 presents the mean scores and standard deviations of the responses of adult education administrators (AEAs), adult literacy facilitators (ALFs), and adult learners on the extent to which integrating synthetic method facilitates the learning of adults in adult basic literacy education program (ABLEP) in Enugu State, Nigeria. From the data on the Table, item 7 was rated highest $\left(1^{\text {st }}\right)$, while items 10 and 12 were rated lowest $\left(5^{\text {th }}\right)$. However, all the mean scores were within the real limit of $2.50-3.49$. The data indicated that all the items (items 7-12) had mean scores of $3.18,3.05,3.14,2.87,3.05$, and 2.87 , respectively. Their mean values ranged from 2.87-3.18, showing that integrating synthetic method facilitates the learning of adults to a moderate extent on the six items. The mean scores had respective standard deviation of $0.90,0.94,0.87,0.96,0.91$ and 1.05 . The standard deviation that were between 0.87 and 1.05 suggested that the responses were clustered around the mean and that the scores of the respondents were similiar. On the whole, the grand mean (3.02 \pm 0.72$)$ indicated that the respondents agreed that integrating synthetic method facilitated the learning of adults in ABLEP to a moderate extent.

Hypothesis two was tested below to further examine the different reactions among adult education administrators, adult literacy facilitators, and adult learners:

$\mathrm{HO}_{2}$ : There is no significant difference among the mean ratings of the adult education administrators, adult literacy facilitators, and adult learners on the extent to which integrating synthetic method facilitates the learning of adults in ABLEP in Enugu State.

To test hypothesis one, Analysis of Variance (ANOVA) was computed on the disparity between the adult education administrators, adult literacy facilitators, and adult learners, and the findings are reported in Table 4 below: 
Table 4. Summary of the ANOVA ratings of respondents on the extent of integrating synthetic method to facilitate the learning of adults in ABLEP in Enugu State, Nigeria

$\mathrm{t}$-Critical $=1.960$

\begin{tabular}{lllllll}
\hline & Sum of Squares & df & Mean Square & F & Sig. & Decision \\
\hline Between Groups & 14.77 & 2 & 7.38 & & & \\
Within Groups & 442.51 & 877 & .51 & 14.63 & .00 & Rejected \\
Total & 457.28 & 879 & & & & \\
\hline
\end{tabular}

Table 4 shows the ANOVA for testing null hypothesis two $\left(\mathrm{HO}_{2}\right)$. The result showed that the F-ratio of 14.63 with an associated exact probability value of 0.00 was obtained. The correct probability value of 0.00 was less than the 0.05 level of significance set as a benchmark. As such, the hypothesis was rejected suggesting that the mean ratings of the adult education administrators, adult literacy facilitators, and adult learners differ significantly on the extent to which integrating synthetic method facilitated the learning of adults in ABLEP in Enugu State, Nigeria.

\section{Discussion of the Findings}

The findings of the study were discussed under the following sub-headings:

\subsection{Extent of Integrating Analytic Method to Facilitate the Learning of Adults in Adult Basic Literacy Education Program}

The results of the study revealed that to a moderate extent, a large element of language was introduced before small elements, the basis for studying small units through the understanding of the larger units was provided, individual words and groups into letters and syllables were reduced, and learners were made to write what they have been taught. Others are achieving mastery of the learning task through structural exercises and using not more than four words in a sentence at a time. The study's results were consistent with the results of Chandrasekar (2002), Nzeneri (2008), and Scheffel, et al. (2014) which asserted that integrating analytic method to facilitate the learning of adults involves tailoring the educational opportunities of the adult learners' need and ability through actions such as teaching adult learners to write what they have been taught and breaking a larger unit down into words, syllables, and letters by introducing large elements of language before small elements.

Machobane (2010) affirmed that learning through the integration of analytic method starts with small sentences, stories that will be breaking into letters of alphabets. Nzeneri (2008) noted that analytic method makes the learners to recognize the word, phrase, and sentence as a whole by reducing them into letters and syllables, thereby providing the basis for studying small units through the understanding of the larger units. According to and Bienkowski, et al. (2012), it also centers on incorporating established approaches and models to tackle problems impacting adult learners and the organizational learning environment by achieving mastery of the learning task through structural exercises thereby making learners write what they have been taught.

The first hypothesis (H01) was based on figuring out if there is any substantial difference between adult education administrators (AEAs), adult literacy facilitators (ALFs), and adult learners' mean ratings on the extent to which integrating analytic method facilitated the learning of adults in ABLEP in Enugu State, Nigeria. The F-ratio of 17.80 , which is greater than the t-Critical value of 1.960 at 0.00 significant point, indicated the rejection of the null hypothesis. Therefore, the AEAs, ALFs, and adult learners did not agree on equal parameters on the extent to which integrating analytic method facilitated the learning of adults in ABLEP in Enugu State, Nigeria. The discrepancy in the degree of agreement might emanate from the fact that many of the adult learners are not familiar with analytic method as a creative method employed by the AEAs and ALFs in ABLEP.

\subsection{Extent of Integrating Synthetic Method to Facilitate the Learning of Adults in Adult Basic Education Literacy Program}

The study's results revealed that to a moderate extent, elements of language started from the simplest to the highest, letters are combined to form a syllable, letters are taught one by one, vowels are taught before consonants, letters are associated with the speech sounds, and consonants are combined with vowels. Supporting the findings, Okenimkpe (2003) affirmed that synthetic method begins teaching reading and writing with the simplest elements of language and proceeds to the largest units, introducing vowels before consonants and using pictures and objects that resemble the letters. The method also guides learners to recognize that letters are combined to form a syllable; syllables are combined to form a word, while words are combined to form a phrase and then a sentence (Nzeneri, 2008). The adults are taught how to construct words by combining already learned letters, often even rendering 
meaningless 'names' by these combinations (Chandrasekar, 2002). The method involves showing a picture of an object to the adult learners and asking them to pronounce the name of the object.

The synthetic technique uses alphabets or letters of the alphabets, and enables learners to learn the syllable block, their sounds and pronunciations and then advance into combining them to form a whole, which is word, phrase, or sentence. If the learners know certain sounds, they can use the information to read words by decoding, or write words by encoding, as they can build up and break down words (Ehri, Nunes, Stahl, \& Willows, 2001). The technique associates letters with the speech sounds which the letters represent, and describes how consonants are combined with vowels (Obi, 2006). The synthetic method is based on facilitating to the learners the sounds of the 44 phonemes in English sequentially and the corresponding letters, from the simplest elements of the language to the highest one (Ehri et al., 2001).

The second hypothesis $\left(\mathrm{HO}_{2}\right)$ centered on finding out if there is any significant difference among the mean ratings of the AEAs, ALFs, and adult learners on the extent to which integrating synthetic method facilitated the learning of adults in ABLEP in Enugu State, Nigeria. The grand F-ratio of 14.63, which is greater than the t-Critical value of 1.960 at 0.00 significant point, indicated the rejection of the null hypothesis. Therefore, the hypothesis showed that AEAs, ALFs, and adult learners did not agree on equal parameters on the extent to which integrating synthetic method facilitated the learning of adults in ABLEP in Enugu State, Nigeria. The observed disparity can be attributed to the high self-rating of AEAs and ALFs, even though there was no agreement on ranking trend between them.

Here lies the need for improving adult basic literacy education program in Enugu State, Nigeria, through the integration of creativity in the facilitation of adult learning. Such creative methods that need to be integrated are analytic and synthetic methods.

\section{Conclusion}

The study assessed the extent to which integrating analytic method facilitates the learning of adults in ABLEP in Enugu State, Nigeria. It was done with the aim of increasing awareness of the need for creativity in the facilitation of adult learning in ABLEP in Nigeria. The study's results revealed that integrating analytic method to facilitate the learning of adults by using not more than four words in a sentence at a time, achieving mastery of the learning task through structural exercises, and making learners to write what they have been taught was to a moderate extent. It implied that Enugu State Agency for Mass Literacy, Adult and Non-Formal Education, through AEAs, need to increase the teaching and learning methods by developing and reviewing facilitating strategies. This is to have a shift from a moderate extent to a very great extent on the integration of the analytic method in facilitating the learning of adults in ABLEP.

The study further revealed that the extent of integrating synthetic method to facilitate the learning of adults was to a moderate extent as facilitators do not teach vowels before consonants, and do not describe how consonants are combined with vowels. Therefore, adult literacy facilitators need to realize that learning opportunities are based on achieving mastery of the learning task through structural exercises, using not more than four words in a sentence at a time, associating letters with the speech sounds which the letters represent, and describing how consonants are combined with vowels. As such, they ought to be well-equipped to prepare the adult learners for the world of work.

\section{Recommendations}

The researchers gave the following recommendations based on the results of the study:

1) Adult literacy facilitators should employ creativity in facilitating adult learning by integrating different facilitating methods. This will allow them to discover what adult learners already know about the subject to be discussed.

2) Adult literacy facilitators should help adult learners master a concept by providing support. The support can be in the form of outlines, recommended documents, storyboards, or key questions. The support and guidance provided to learners facilitate the internalization of the knowledge needed to complete the task.

3) Adult literacy facilitators should develop learning objectives based on learners' needs, interests, and skills. Based on this, they should design sequential activities to achieve the objectives, work collaboratively with the adult learners to select methods, materials, and resources.

4) State agency for mass literacy, adult and non-formal education should encourage adult literacy facilitators to create personalized programs of instruction and lesson plans that are based on the adult learners' skill level and learning style. 


\section{Competing Interests Statement}

The authors hereby declare that there are no competing or potential conflicts of interest.

\section{References}

Audi, O., Ayodo, T. M. O., \& Simatwa, E. (2014). Adult literacy program in Vihiga: The capacity of facilitators to produce learners with functional skills. Retrieved from http://www.ijhssnet.com/journals/Vol_4_No_5_March_2014/31.pdf

Audi, O., Ayodo, T. M. O., Simatwa, E., \& Othuon, L. A. (2014). Evaluation of facilitators' skills in assessing the achievement of in literacy program in Vihiga. Greener Journal of Education and Training Studies, 2(3), 058-063. https://doi.org/10.15580/GJETS.2014.3.111813967

Berdie, S. D. D. (2017). Facilitation of adult literacy: A case within the Ghana National Functional Literacy Program. Retrieved from http://sro.sussex.ac.uk/id/eprint/68304/1/Berdie,\%20Susan\%20Delali\%20Doe.pdf

Bhola, H. S. (2000). A discourse on impact evaluation: A model and its application to a literacy intervention in Ghana. Evaluation, 6(2), 161-178. https://doi.org/10.1177/13563890022209190

Bienkowski, M., Feng, M., \& Means, B. (2012). Enhancing teaching and learning through educational data mining and learning analytics: An issue brief. Washington, D.C.: U.S. Department of Education, Office of Educational Technology. http://www.ed.gov/technology

Biney, I. K. (2014). ADLT 101: Introduction to adult education study guide for undergraduates level 100. Legon, Accra: School of Continuing and Distance Education, University of Ghana. Retrieved from https://godsonug.files.wordpress.com/2017/09/study-guide.pdf

Bocconi, S., Kampylis, P. G., \& Punie, Y. (2012). Innovating learning: Key elements for developing creative classrooms in Europe. Scientific and Policy Report by the Joint Research Centre of the European Commission. http://is.jrc.ec.europa.eu/pages/EAP/SCALECCR.html.

Chandrasekar, R. (2002). Education: Nitty-gritty of teaching and learning. The Hindu Online edition of India's National Newspaper Tuesday, Aug 13. Retrieved from https://www.thehindu.com/thehindu/edu/2002/08/13/stories/2002081300040200.htm.

Carter, R. (2000). Mapping the mind. California: University Press. https://www.amazon.co.uk/Mapping-Mind-Rita-Carter/dp/0753827956

Creswell, J.W. (2012). Educational research; Planning, conducting, and evaluating quantitative and qualitative research. Boston: Pearson Education, Inc. Retrieved from http://basu.nahad.ir/uploads/creswell.pdf.

Du Toit, P. H. (2002). Reader for postgraduate studies in professional development and facilitating learning. Pretoria: University Press.

Ehri, L. C., Nunes, S. R., Stahl, S. A., \& Willows, D. M. (2001). Systematic Phonics Instruction Helps Students Learn to Read: Evidence from the National Reading Panel's Meta- Analysis. Review of Educational Research, 71(3), 393-447. https://doi.org/10.3102/00346543071003393

Ezema, J. O., Ukwuaba, L. L., \& Ali, M. A. (2018). Utilizing basic literacy as an adult education program in achieving sustainable human resource development in Enugu State, Nigeria. Journal of Nigerian National Council of Adult Education, 23(11), 154-165.

Federal Republic of Nigeria. (2013). National policy on education. Lagos: NERDC. https://issuu.com/esspin/docs/national_policy_on_education

Heckmann, F. (2004). Integration: Conceptual issues and definitions. Paper presented at the IMISCOE Cluster B5 Conference in Lisbon, July 16-17.

Kamp, M. (2011). Facilitation skills and methods of adult education: A guide for civic education at grassroots levels. Retrieved from https://www.kas.de/c/document_library/get_file?uuid=8159de20-2e04-f18b-002e8cf996146504\&groupId $=252038$

Lesgold, A. M., \& Welch-Ross, M. (Eds.). (2012). Literacy Instruction for Adults. In Improving Adult Literacy Instruction: Options for Practice and Research (pp. 70-105). Washington, DC: The National Academies Press.

Machobane, A. M. (2010). Strategies for facilitating learning in adult basic education and training (Master's thesis), University of Pretoria. Retrieved from https://repository.up.ac.za/bitstream/handle/ 
2263/27925/dissertation.pdf?sequence $=1 \&$ isAllowed $=y$

Meneely, J., \& Portillo, M. (2005). The adaptable mind in design: Relating personality, cognitive style and creative performance. $\quad$ Creativity Research $\quad$ Journal, $\quad 17(2-3), \quad 155-166$. https://doi.org/10.1207/s15326934crj1702\&3_3

National Commission for Mass Literacy, Adult and Non-Formal Education. (2012). Facilitators' handbook for non-formal education. Abuja: NMEC.

Nzeneri, I. S. (2008). Handbook on adult education: Principles and practices. Uyo: Abigab Associates.

Obetta, K. C., \& Oreh, C. I. (2018). Reduction in boys' drop-out-of-school syndrome: A step towards a new era in Enugu State, Nigeria. Review of Education (Journal of Institute of Education, University of Nigeria, Nsukka), 30(1), 141-154.

Obi, G. O. (2006). Dimensions and issues in adult literacy. Nsukka: Ephrata Publishers.

Obidiegwu, U. J. (2013). Planning effective education and training programmes in adult education. In W. E. Obiozor \& U. J. Obidiegwu (Eds.), Globalization of Adult Education: Theories and Strategies for Instructors (pp. 120-132). Onitsha: ONESTREET.

Odo, R. S. (2015). Contributions of National Mass Education Commission (NMEC) in Reducing Illiteracy in South East Nigeria (Unpublished master's thesis. University of Nigeria, Nsukka).

Okenimkoe, M. N. (2003). Adult education teaching methods: Principles, procedures and techniques. Lagos: University of Lagos Press.

Penninx, R., \& Garcés-Mascareñas, B. (2016). The concept of integration as an analytical tool and as a policy concept. In B. Garcés-Mascareñas \& R. Penninx (Eds.), Integration Processes and Policies in Europe: Contexts, Levels and Actors. IMISCOE Research Series (pp. 11-29). Cham: Springer. https://doi.org/10.1007/978-3-319-21674-4_2

Scheffel, M., Drachsler, H., Stoyanov S., \& Specht, M. (2014). Quality indicators for learning analytics. Educational Technology \& Society, 17(4), 117-132. Retrieved from https://pdfs.semanticscholar.org/e433/4e54049a37beca208bd7aa4b4b57cc5f551d.pdf?

UNESCO Global Education Monitoring Report. (2016). Education for People and Planet: Creating Sustainable Futures for All. Paris: UNESCO. Retrieved from http://www.adeanet.org/en/system/files/245752e_0.pdf

\section{Copyrights}

Copyright for this article is retained by the author(s), with first publication rights granted to the journal.

This is an open-access article distributed under the terms and conditions of the Creative Commons Attribution license (http://creativecommons.org/licenses/by/4.0/). 